Original Research

\title{
Genetic Variants of Targetable Cancer-related Genes in Vestibular Schwannomas
}

Alvin Ho-Kwan Cheung ${ }^{1}$, Nancy Bo-Yin Tsui ${ }^{2}$, William Chi-Shing Cho ${ }^{3}$, Xiao-Meng Pei ${ }^{2}$, Yin-Kwan Evelyn Wong ${ }^{2}$, Hin-Fung Andy Tsang ${ }^{2}$, Gilberto Ka-Kit Leung ${ }^{1}$, Sze-Chuen Cesar Wong ${ }^{2,}{ }^{*}$

1. Neurosurgery, Department of Surgery, University of Hong Kong and Queen Mary Hospital, Hong Kong; E-Mails: cheung_hokwan@hotmail.com; gilberto@hku.edu.hk

2. Health Technology and Informatics, Hong Kong Polytechnic University, Hong Kong; E-Mails: cesar.wong@polyu.edu.hk; peixiaomeng@sina.com; evelynwong0723@gmail.com; andy_thf@yahoo.com.hk; cesar01@netvigator.com

3. Department of Clinical Oncology, Queen Elizabeth Hospital, Hong Kong; E-Mail: chocs@ha.org.hk

* Correspondence: Sze-Chuen Cesar Wong; E-Mail: cesar.wong@polyu.edu.hk

Academic Editor: Lunawati L Bennett

Special Issue: $\underline{\text { Cancer Genetics and Epigenetics Alterations }}$

OBM Genetics

2020, volume 4, issue 2

doi:10.21926/obm.genet.2002112
Received: May 02, 2020

Accepted: June 23, 2020

Published: June 28, 2020

\begin{abstract}
Background: Vestibular schwannoma is an intracranial tumor which can lead to devastating neurological deficit and is prone to recurrence after surgery. Patients with inherited neurofibromatosis type 2 (NF2) syndrome are particularly susceptible to bilateral and aggressive schwannomas. However, the genome of vestibular schwannomas is not well known. There is an imminent need of developing effective chemotherapeutic agents either as a primary treatment modality or as adjuvant therapy for these patients. Methods: Here, we subjected both sporadic and NF2-related schwannomas to high-throughput DNA sequencing using a panel of therapeutically important cancer-related genes, in order to determine if targetable genetic changes are present in schwannomas. Results: A number of variants were detected in the genes NRAS, PDGFRA, KIT, and EGFR, in both sporadic and
\end{abstract}

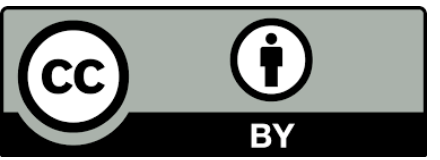

(C) 2020 by the author. This is an open access article distributed under the conditions of the Creative Commons by Attribution License, which permits unrestricted use, distribution, and reproduction in any medium or format, provided the original work is correctly cited. 
NF2-related cases. The results were confirmed by Sanger sequencing. Conclusion: Our study successfully detected some genetic variants in important cancer-related genes in schwannomas, and further elucidation of their relationship to drug-response will be pursued.

\section{Keywords}

Vestibular schwannoma; genetic variants; targeted DNA sequencing; targeted therapy

\section{Introduction}

Vestibular schwannoma is a benign tumor arising from the vestibular nerve usually at the junction between cerebellum and pons. It is one of the commonest intracranial tumors with an annual incidence of up to 1.9 per 100,000 population [1]. Although it is a benign tumor, it may grow to large size causing compression of brainstem and cerebellum. Subsequently, the patient may develop deficits in the cranial nerves, which can result in disfiguring facial paralysis or numbness, difficulty in swallowing, and hearing loss [2,3]. The mainstay of treatment is surgery or stereotactic radiosurgery [4]. Unfortunately, because the lesions can be deep-seated, surgical clearance may often be incomplete [5]. Recurrence can also occur especially with tumors associated with neurofibromatosis 2 (NF2) syndrome, a congenital syndrome which predisposes to bilateral schwannomas and other multifocal brain tumors [6]. Moreover, mutations in the NF2 tumor suppressor gene have been identified in not only NF2-related tumors but also sporadic vestibular schwannomas [7]. These patients may have complete deafness due to destruction of bilateral acoustic apparatus [6].

There is an imminent need of developing effective chemotherapeutic agents either as a primary treatment modality or as adjuvant therapy for patients with residual tumors. Some novel targeted-therapeutic agents, such as bevacizumab [8] and imatinib [9], had been tried with early promise, although progress on their clinical applications is still in the primitive stage.

There are many other potential targeted-therapeutic drugs currently available for treating cancers, acting on genes which harbour variants that can drastically increase tumor response. In order to select new drugs suitable for further trials in patients with schwannomas, we carried out screening on a number of key cancer genes whose mutations have been demonstrated to predict tumor susceptibility to known targeted therapeutic agents.

With the use of next-generation sequencing (NGS), the screening includes 8 key cancer genes implicated in prognostication and prediction of treatment response in many cancers, namely BRAF, EGFR, IDH1, IDH2, KIT, KRAS, NRAS, PDGFRA, as laid down by the National Comprehensive Cancer Network Taskforce [10]. We selected this panel for the preliminary analysis for several reasons. These genes are targets of many currently available targeted therapeutics, for instance KIT and PDGFRA by imatanib [11]; BRAF by vemurafenib, Dabrafenib, and trametinib; KRAS by Cetuximab; and EGFR by Gefitinib. IDH1 and IDH2 have critical importance in the oncogenesis of brain tumors [12]. Up to $80 \%$ of high grade gliomas harbour IDH1 mutations [13]. This gene also predicts response of gliomas to the drug temozolimide [12]. BRAF, KRAS, NRAS and EGFR, play crucial role in the MAPK and receptor tyrosine kinase (RTK) pathways [14]. These pathways have great potential as targets for novel anti-cancer drugs. 


\section{Materials and Methods}

\subsection{Patient Samples}

Paired tissue samples and blood samples were obtained from the Department of Surgery, Queen Mary Hospital and the University of Hong Kong, with ethics approval and patient consent.

\subsection{Patient Samples, DNA Extraction and Next-Generation Sequencing}

Frozen schwannoma tissue and paired blood samples were obtained from the Department of Surgery, Queen Mary Hospital and the University of Hong Kong, with patient consent. DNA was extracted from these tissues and blood by QIAamp DNA Mini Kit (Qiagen, Hilden, Germany) and QIAamp DNA Blood Mini Kit (Qiagen), respectively, following the manufacturer's instructions. DNA of targeted gene regions was amplified with multiplex PCR primer sets provided in the Human Tumor Actionable Mutations Panel (Qiagen) and the GeneRead DNAseq Panel PCR Kit (Qiagen) according to the manufacturer's instructions. Sequencing libraries were then prepared using the NEBNext Ultra DNA Library Prep Kit (New England BioLabs, Herts, UK). Libraries from individual samples were labelled with distinctive index sequences. The libraries were sequenced on the MiSeq Sequencer (Illumina, San Diego, USA) by the MiSeq Reagent Kit v3 (Illumina) using the 150 cycles single-end protocol. Sequence variations were identified by the GeneRead Targeted Exon Enrichment Panel Data Analysis pipeline (Qiagen).

\subsubsection{Validation by Sanger Sequencing}

Prior to sequencing reaction, PCR was performed to amplify the SNP flanking sequences in a 15 $\mu \mathrm{L}$ reaction volume with 0.3 unit HotStarTaq Plus DNA Polymerase (Qiagen, Hilden, Germany), 1x PCR buffer (which contains $\mathrm{KCl}$ and $\left(\mathrm{NH}_{4}\right)_{2} \mathrm{SO}_{4}$ ), $2.5 \mathrm{mM} \mathrm{MgCl}_{2}, 0.2 \mathrm{mM}$ of each dNTP (deoxyribonucleotide triphosphate), $0.3 \mu \mathrm{M}$ of the forward and reverse primers using $30 \mathrm{ng}$ of DNA. Flanking sequences of the SNPs were obtained from the 1000 Genomes Project data [15] for primer design. Primers were designed using OLIGO version 6.62 software (Molecular Biology Insights, Inc., USA) (Table 1 ) to have similar melting temperature $\left(T \mathrm{~m},{ }^{\circ} \mathrm{C}\right)$. Amplification was performed with Veriti ${ }^{\circledR}$ Thermal Cycler from Applied Biosystems (Waltham, MA USA), PCR condition was $95^{\circ} \mathrm{C}$ for $5 \mathrm{~min}$; 30 cycles with denaturation at $95^{\circ} \mathrm{C}$ for $30 \mathrm{sec}$, annealing at $60^{\circ} \mathrm{C}$ for $25 \mathrm{sec}$, and extension at $72^{\circ} \mathrm{C}$ for $30 \mathrm{sec} ; 1 \mathrm{cycle}$ at $72^{\circ} \mathrm{C}$ for $5 \mathrm{~min}$; and a final hold at $15^{\circ} \mathrm{C}$. PCR products were analyzed by electrophoresis on $1.5 \%$ agarose gels pre-stained with SYBR Safe DNA Gel Stain (Thermo Fisher Scientific, Waltham, MA USA).

\subsubsection{DNA Sequencing}

Post-PCR enzyme purification was performed with the following condition: 1 unit of Exonuclease I, E. coli (New England Biolabs, Inc. (NEB, Ipswich, MA, USA)), 1 unit of Antarctic phosphatase (NEB), $0.1 \mu \mathrm{L}$ of both 10x Exonuclease I buffer and 10x Antarctic phosphatase buffer, and $0.55 \mu \mathrm{L}$ of $\mathrm{ddH}_{2} \mathrm{O}$ were added to each sample $(5 \mu \mathrm{L})$. The pool of PCR product and enzyme mix was incubated at $37^{\circ} \mathrm{C}$ for $30 \mathrm{~min}$ followed by $80^{\circ} \mathrm{C}$ for $20 \mathrm{~min}$ to inactivate the enzyme. Cycle sequencing was performed with BigDye ${ }^{\circledR}$ Terminator v1.1 (Thermo Fisher Scientific, Waltham, MA USA) in a final volume of $10 \mu \mathrm{L}$. Each reaction contained $6 \mu \mathrm{L}$ of purified PCR product, $2 \mu \mathrm{L}$ of 
BigDye, $1.6 \mathrm{pmol}$ of primer (all the SNPs were performed with the same forward primers used in PCR amplification [Table 1]), and $0.4 \mu \mathrm{L}$ of $\mathrm{ddH}_{2} \mathrm{O}$ to make up the final volume. Cycle sequencing was performed with Veriti ${ }^{\circledR}$ Thermal Cycler from Applied Biosystems (Waltham, MA USA); condition was $96^{\circ} \mathrm{C}$ for $1 \mathrm{~min} ; 30$ cycles of $96^{\circ} \mathrm{C}$ for 10 seconds, $55^{\circ} \mathrm{C}$ for $30 \mathrm{sec}$, and $60^{\circ} \mathrm{C}$ for $6 \mathrm{~min}$. The cycle sequencing products were then purified using the ethanol/ sodium acetate precipitation method and then resuspended in $15 \mathrm{uL} \mathrm{Hi}$-Di $^{\mathrm{TM}}$ formamide (Thermo Fisher Scientific, Waltham, MA USA). The electrophoretic separation was performed on ABI PRISM 3130 Genetic Analyzer (Applied Biosystems, Waltham, MA USA), and analyzed with Sequencing Analysis Software V5.3.1 (Applied Biosystems, Waltham, MA USA).

Table 1 Primers used in PCR and sequencing of the variants.

\begin{tabular}{|c|c|c|c|}
\hline Gene & Chr & dbSNP ID & Primer sequences $\left(5^{\prime}>3^{\prime}\right)$ \\
\hline \multirow[t]{2}{*}{ NRAS } & chr1 & rs969273 & F: CCT TCG CCT GTC CTC ATG TAT TG \\
\hline & & & R: GTG GGT TTT CTT TTA TGT AGG GTG ATA TTG \\
\hline \multirow[t]{2}{*}{ PDGFRA } & chr4 & rs2228230 & F: TCT GTT GGG AGT GGG TGG AGT G \\
\hline & & & R: ATT AAA GTG AAG GAG GAT GAG CCT GAC \\
\hline \multirow[t]{2}{*}{ KIT } & chr4 & rs1008658 & F: TTT CTT TTC TCC TCC AAC CTA ATA GTG \\
\hline & & & R: CCT TCA CAT GCC CCA AAA TTA CAC \\
\hline \multirow[t]{2}{*}{ EGFR } & chr7 & rs1050171 & F: GCA CAG CTT TTC CTC CAT GAG TAC \\
\hline & & & R: TAT CTC CCT TCC CTG ATT ACC TTT G \\
\hline \multirow[t]{2}{*}{ EGFR } & chr7 & rs1140475 & F: TGA AAC AGA TAC TGC TAT TAC CCC AC \\
\hline & & & R: TGC CCA ATG AGT CAA GAA GTG TC \\
\hline \multirow[t]{2}{*}{ EGFR } & chr7 & rs10241451 & F: CTC CGA CTC CTC CTT TAT CCA ATG \\
\hline & & & R: CTT CCC TGA TTA CCT TTG CGA TCT G \\
\hline
\end{tabular}

Note: Abbreviations: Chr: chromosome; SNP, single nucleotide polymorphism; PCR, polymerase chain reaction.

Primers used for PCR and sequencing. Primer names starting with F indicate forward primers; names with $\mathrm{R}$, reverse primers. Note that all sequencing reactions were performed with the forward primers $(F)$.

\section{Results}

Six tumor samples, including 3 sporadic cases and 3 NF2 cases, along with their paired leukocytes control, were selected for this analysis. The patient demographics are shown in Table 2. The quantity and quality of DNA were satisfactory for subsequent targeted sequencing for 8 cancer genes.

For the 3 paired NF2-associated tumor and 3 paired sporadic tumor samples we studied, we achieved an average depth of 5,241x and an average of 498,993 reads for each sample. A total number of 6 variants were discovered for the tumors (Table 3 ). The variants were belonged to the 4 genes NRAS, PDGFRA, KIT, and EGFR. Of the variants, five occurred in sporadic tumors and five occurred in NF2-associated tumor. Therefore, NF2-associated tumors did not appear to have more variants in the sequenced genes compared to sporadic tumors. The variants were also present in blood control. These variants are single nucleotide polymorphisms (SNP), which may be related to the Chinese ethnicity in all patients. They are either located at the intron regions, or are 
synonymous substitution in the exons. Each variant had an average of 5224x coverage. The results were validated by Sanger sequencing and the results were shown in Table 4 and Figure 1.

Table 2 Patient and tumor characteristics of vestibular schwannoma clinical specimens.

\begin{tabular}{|c|c|c|c|c|c|c|c|c|c|}
\hline $\begin{array}{l}\text { Patient } \\
\text { number }\end{array}$ & Group & Age & Sex & $\begin{array}{l}\text { Largest } \\
\text { Dimension } \\
(\mathrm{cm})\end{array}$ & Side & $\begin{array}{l}\text { Latest } \\
\text { Reassessment }\end{array}$ & $\begin{array}{l}\text { L } \\
\text { Hearing }\end{array}$ & R Hearing & $\begin{array}{l}\text { Facial } \\
\text { Nerve }\end{array}$ \\
\hline 1 & NF2 & 46 & $\mathrm{~F}$ & 4.5 & $L$ & $\begin{array}{l}\text { Static } \\
\text { contralateral } \\
\text { tumor }\end{array}$ & Loss & Impaired & \\
\hline 2 & NF2 & 35 & $F$ & 4.0 & $\mathrm{R}$ & Multiple tumors & Loss & Impaired & L palsy \\
\hline 3 & NF2 & 21 & $M$ & 3.5 & $\mathrm{R}$ & Multiple tumors & Normal & Impaired & \\
\hline 4 & Sporadic & 48 & $\mathrm{~F}$ & 4.5 & $\mathrm{R}$ & Static residual & Normal & Normal & R palsy \\
\hline 5 & Sporadic & 56 & $\mathrm{~F}$ & 4.3 & $\mathrm{~L}$ & Static residual & Loss & Normal & \\
\hline 6 & Sporadic & 55 & $\mathrm{~F}$ & 4.0 & $\mathrm{R}$ & Static residual & Normal & Loss & R palsy \\
\hline
\end{tabular}

Note: Patients' age at operation are provided. Latest reassessments of tumor status are by magnetic resonance imaging. Neurological assessments are performed by examination in follow-up clinic. These were latest reassessments as of year 2015. Ethnicity of all patients is Chinese. NF2, Neurofibromatosis type 2. L, left. R, right.

Table 3 Genetic variants found in vestibular schwannoma (VS) samples among the genes BRAF, EGFR, IDH1, IDH2, KIT, KRAS, NRAS, PDGFRA.

\begin{tabular}{|c|c|c|c|c|c|c|c|}
\hline $\begin{array}{l}\text { Gene } \\
\text { Name }\end{array}$ & Chromosome & dbSNP ID & Ref & Variant & $\begin{array}{l}\text { Patient } \\
\#\end{array}$ & $\begin{array}{l}\text { lowest filtered } \\
\text { coverage }\end{array}$ & Variant frequency \\
\hline NRAS & chr1 & rs969273 & G & $A$ & 1 & 24 & $1.0^{1}$ \\
\hline PDGFRA & chr4 & rs2228230 & $\mathrm{C}$ & $\mathrm{T}$ & 1,6 & 6,189 & $0.498^{1}, 0.479^{6}$ \\
\hline KIT & chr4 & rs1008658 & $\mathrm{T}$ & C & All & 1,536 & $\begin{array}{l}1.0^{1}, 0.528^{2} \\
0.998^{3}, 0.491^{4} \\
0.999^{5}, 1.0^{6}\end{array}$ \\
\hline EGFR & chr7 & rs1050171 & G & $A$ & 1,5 & 2,551 & $0.467^{1}, 0.483^{5}$ \\
\hline EGFR & chr7 & rs1140475 & $\mathrm{T}$ & C & All & 4,083 & $\begin{array}{l}0.999^{1}, 0.999^{2} \\
0.515^{3}, 0.499^{4} \\
0.999^{5}, 0.9999^{6}\end{array}$ \\
\hline EGFR & chr7 & rs10241451 & $\mathrm{T}$ & C & 5 & 1,398 & $0.465^{5}$ \\
\hline
\end{tabular}

Note: All are single nucleotide polymorphisms with synonymous effect. Tumor samples 1 through 3 are neurofibromatosis 2-associated VS while 4 through 6 are sporadic VS. All genetic variants are also found in leukocyte control. The variant frequency is, by definition, the variant allele coverage over the lowest filtered coverage. Superscript indicates the patient number to which the variant frequency belongs. 
Table 4 Genetic variants validated by Sanger sequencing.

\begin{tabular}{lllllc}
\hline Gene & Chr & dbSNP ID & Ref & Variant & Patient \# (genotype) \\
\hline NRAS & chr1 & rs969273 & G & A & $1(\mathrm{~A} / \mathrm{A})$ \\
PDGFRA & chr4 & rs2228230 & C & T & $1(\mathrm{C} / \mathrm{T}), 6(\mathrm{C} / \mathrm{T})$ \\
KIT & $\mathrm{chr} 4$ & $\mathrm{rs} 1008658$ & $\mathrm{~T}$ & $\mathrm{C}$ & $2(\mathrm{~T} / \mathrm{C}), 4(\mathrm{~T} / \mathrm{C})$ \\
EGFR & $\mathrm{chr} 7$ & $\mathrm{rs} 1050171$ & $\mathrm{G}$ & $\mathrm{A}$ & $1(\mathrm{~A} / \mathrm{A}), 5(\mathrm{G} / \mathrm{A})$ \\
EGFR & $\mathrm{chr7}$ & $\mathrm{rs} 1140475$ & $\mathrm{~T}$ & $\mathrm{C}$ & $3(\mathrm{~T} / \mathrm{C}), 4(\mathrm{~T} / \mathrm{C})$ \\
EGFR & $\mathrm{chr7}$ & $\mathrm{rs} 10241451$ & $\mathrm{~T}$ & $\mathrm{C}$ & $5(\mathrm{~T} / \mathrm{C})$ \\
\hline
\end{tabular}

Note: Abbreviations: Chr: chromosome; SNP, single nucleotide polymorphism; Ref, reference allele.
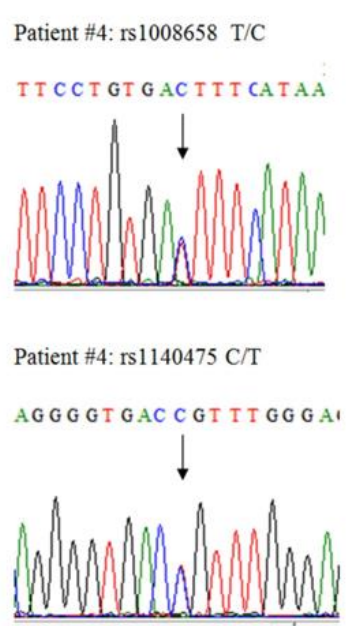

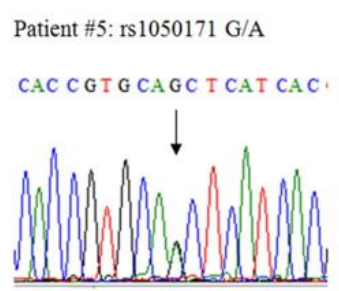

Patient \#1: rs969273 A/A

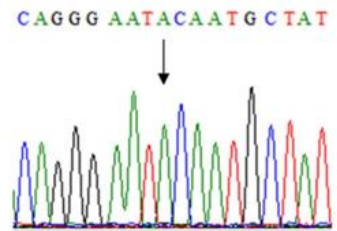

Figure 1 Sanger sequencing validation of variants identified from MiSeq. Results from MiSeq were all successfully validated. The figure shows examples of the variants verified by Sanger sequencing. SNPs are marked with an arrow pointing downwards.

\section{Discussion}

Targeted therapy blocks the growth of cancer cells by interfering with specific targeted molecules needed for carcinogenesis. These molecules may arise from mutations or differential gene expression. Many genetic changes have been found to predict response of targeted therapy in tumors, the investigations of which now being the standard of care in clinical oncology [16]. With the ever-increasing implications of genetics on cancer management, the National Comprehensive Cancer Network Taskforce identified 8 key cancer genes where many of which may serve to predict therapeutic potentials of currently available drugs [10].

To investigate the potential use of currently available targeted therapeutic agents on vestibular schwannoma, we characterized these 8 key cancer genes by using NGS. Compared to traditional sequencing methods, NGS provides a much greater sensitivity of detecting mutations in tumor cells which are often present in small amount, mixed with normal cells. Genetic variants are represented by multiple sequencing fragments (reads) to prove its authenticity. It is also much 
more efficient as it allows parallel sequencing of multiple genes of interest in multiple samples at the same time. The successful validation of those variants using Sanger sequencing in the patient samples can confirm that our targeted sequencing results were accurate.

Genetic variants, at the nucleotide level, include mutations and SNPs. While many mutations such as those of EGFR are classical predictors of drug response, there is growing evidence that many SNPs are also implicated in this regard. For example, a previous study demonstrated a SNP in VEGFR1 correlated with increased expression of VEGFR1, which increased the response rate of bevacizumab in patients with renal cancer [17]. Another polymorphism in the proangiogenetic gene, IL8, was also found to affect response to bevacizumab-based chemotherapy in ovarian cancer [18]. These evidence suggest that SNPs need not be disease-specific to predict drug response. Of the six variants reported in this study, three variants rs2228230, rs1050171, and rs1140475 are classified as benign or likely benign, while the remaining have not been reported in the ClinVar database. Therefore, their clinical significance are to be further elucidated.

In this study, PDGFRA, KIT, and EGFR, which are tyrosine kinase receptor genes, play critical roles in the pathways of interest. PDGFRA gene encodes the alpha-type platelet derived growth factor receptors, whose level has been shown to be up to 40-fold increased in schwannoma tissues [9]. It is targeted by imatinib. Its mutation can also be found in some malignant brain tumors such as gliosarcoma and glioblastoma. The proto-oncogene KIT encodes a receptor tyrosine kinase whose overexpression is documented in many cancers and is increased up to 30fold in schwannomas [9]. The gene is also targeted by imatinib. In schwannoma cell line, imatinib has been shown to reduce the level of PDGFRA and c-kit and its downstream effectors $p$-AKT and p-ERK in the PI3K-AKT and MAPK signalling pathways, respectively. The rate of schwannoma apoptosis is increased [9]. As for the proto-oncogene EGFR, a number of the EGFR family of receptors, such as EGFR, ErbB2, ErbB3, and ErbB4, has been found to be increasingly phosphorylated and overexpressed in vestibular schwannomas [19]. The EGFR family intersects with the VEGF receptor family in the downstream RTK pathways [20]. EGFR inhibitors, such as erlotinib, can inhibit schwannomas in xenograft models [19]. Checking EGFR mutation is now standard practice in treatment of lung cancers as this predicts the response of gefitinib.

NRAS belongs to the RAS family, and is a proto-oncogene which activates downstream pathways such as MAPK and Akt/MTOR pathways [21, 22]. It encodes a GTPase which plays a central role in the signal transduction from the upstream receptor tyrosine kinase. Despite tremendous efforts, effective RAS inhibitors were still largely obscure, with only recent early success [23, 24]. For brain tumor, its reports were predominantly in neuroblastomas. Some evidence suggested that RAS mutation may act in concert with NF2 mutation to promote tumor formation, such as in schwannomas [25].

Ideally, a therapeutic drug targeting the driver mutations of the tumor is most desirable, as this is intuitively most efficacious and leads to least side effects. Targeted therapy to the tumor suppressor gene NF2 is considered difficult, and drugs used in clinical trials are mainly targeted to its downstream signalling pathways, such as the Hippo, or mTOR signalling pathways, with YAP inhibitor verteporfin and mTOR inhibitor everolimus, respectively. Unfortunately, these drugs have currently met with limited success in other NF2-inactivated tumors such as mesothelioma [26]. Further search to identify the key driver genes in schwannomas are important to understand its pathogenesis and therapeutic implications, although vestibular schwannoma may not harbour a large number of mutational events in view of its benign, slow growing nature. 
This report demonstrates that a number of different SNPs can be present in each vestibular schwannoma samples. These polymorphisms can potentially predict treatment response, similar to that illustrated by VEGFR1 and IL8 in the case of bevacizumab (see above) [17]. SNPs can be related to ethnicity. Presence of SNP in the homozygous form suggests that this is likely in the current cohort. This may be a possible mechanism to explain the different tumor sensitivity to targeted therapy among ethnic groups.

\section{Conclusions}

The current findings lead us to suspect that mutational events in vestibular schwannoma may be uncommon, which explains the benign nature of the disease. This is the case in meningiomas, which appear to have significantly less disease-causing mutations than other tumors [27]. Although genetic changes in the current study are likely passenger variants, it remains to be of importance to determine whether they may play a therapeutic or prognostic role in schwannomas, because these genes play key role in other cancers. The current analyses only include a small number of important cancer genes. Many upstream signalling pathways and inter-related to these genes are unknown to-date. The relationship between potential drugs and the schwannoma genome requires further elucidation.

\section{Key Issues}

Vestibular schwannoma is a benign tumor arising from the vestibular nerve usually at the junction between cerebellum and pons. It is one of the commonest intracranial tumors with an annual incidence of up to 1.9 per 100,000 population.

This report demonstrates that a number of different SNPs can be present in each vestibular schwannoma samples. These polymorphisms can potentially predict treatment response, similar to that illustrated by VEGFR1 and IL8 in the case of bevacizumab.

\section{Author Contributions}

Alvin Ho-Kwan Cheung initiated the concept, performed the experiments and wrote the manuscript. Nancy Bo-Yin Tsui performed the experiments. William Chi-Shing Cho, Xiao-Meng Pei, Yin-Kwan Evelyn Wong, Hin-Fung Andy Tsang revised the manuscript and gave valuable comments on it. Gilberto Ka-Kit Leung kindly approve and arrange the specimens for the experiments. SzeChuen Cesar Wong are the overall co-ordinater of this project, design the experiments, revised the manuscript and gave valuable comments on it.

\section{Competing Interests}

The authors declare that they have no competing interests.

\section{References}

1. Babu R, Sharma R, Bagley JH, Hatef J, Friedman AH, Adamson C. Vestibular schwannomas in the modern era: Epidemiology, treatment trends, and disparities in management. J Neurosurg. 2013; 119: 121-130. 
2. Charabi S, Thomsen J, Mantoni M, Charabi B, Jørgensen B, Børgesen SE, et al. Acoustic neuroma (vestibular schwannoma): Growth and surgical and nonsurgical consequences of the wait-and-see policy. Otolaryngol Head Neck Surg. 1995; 113: 5-14.

3. Godefroy WP, Kaptein AA, Vogel JJ, van der Mey AG. Conservative treatment of vestibular schwannoma: A follow-up study on clinical and quality-of-life outcome. Otol Neurotol. 2009; 30: 968-974.

4. $13^{\text {th }}$ International Stereotactic Radiosurgery Society Congress (ISRS 2017). J Radiosurg SBRT. 2017; 5: 1-205.

5. Nadol Jr JB, Diamond PF, Thornton AR. Correlation of hearing loss and radiologic dimensions of vestibular schwannomas (acoustic Neuromas). Otol Neurotol. 1996; 17: 312-316.

6. Brackmann DE, Owens RM, Friedman RA, Hitselberger WE, De la Cruz A, House JW, et al. Prognostic factors for hearing preservation in vestibular schwannoma surgery. Otol Neurotol. 2000; 21: 417-424.

7. Lee JD, Kwon TJ, Kim UK, Lee WS. Genetic and epigenetic alterations of the NF2 gene in sporadic vestibular schwannomas. PLoS One. 2012; 7: e30418.

8. Plotkin SR, Stemmer-Rachamimov AO, Barker FG, Halpin C, Padera TP, Tyrrell A, et al. Hearing improvement after bevacizumab in patients with neurofibromatosis type $2 . \mathrm{N}$ Engl J Med. 2009; 361: 358-367.

9. Mukherjee J, Kamnasaran D, Balasubramaniam A, Radovanovic I, Zadeh G, Kiehl TR, et al. Human schwannomas express activated platelet-derived growth factor receptors and c-kit and are growth inhibited by Gleevec (Imatinib Mesylate). Cancer Res. 2009; 69: 5099-5107.

10. Febbo PG, Ladanyi M, Aldape KD, De Marzo AM, Hammond ME, Hayes DF, et al. NCCN Task Force report: Evaluating the clinical utility of tumor markers in oncology. J Natl Compr Canc Netw. 2011; 9: S1-32.

11. Heinrich MC, Corless CL, Demetri GD, Blanke CD, von Mehren M, Joensuu $H$, et al. Kinase mutations and imatinib response in patients with metastatic gastrointestinal stromal tumor. J Clin Oncol. 2003; 21: 4342-4349.

12. Houillier C, Wang X, Kaloshi G, Mokhtari K, Guillevin R, Laffaire J, et al. IDH1 or IDH2 mutations predict longer survival and response to temozolomide in low-grade gliomas. Neurology. 2010; 75: 1560-1566.

13. Yan $H$, Parsons DW, Jin G, McLendon R, Rasheed BA, Yuan W, et al. IDH1 and IDH2 mutations in gliomas. N Engl J Med. 2009; 360: 765-773.

14. Rini BI, Small EJ. Biology and clinical development of vascular endothelial growth factortargeted therapy in renal cell carcinoma. J Clin Oncol. 2005; 23: 1028-1043.

15. The Genomes Project C. A global reference for human genetic variation. Nature. 2015; 526: 68-74.

16. Hyman DM, Taylor BS, Baselga J. Implementing genome-driven oncology. Cell. 2017; 168 : 584-599.

17. Lambrechts D, Claes B, Delmar P, Reumers J, Mazzone M, Yesilyurt BT, et al. VEGF pathway genetic variants as biomarkers of treatment outcome with bevacizumab: An analysis of data from the AViTA and AVOREN randomised trials. Lancet Oncol. 2012; 13: 724-733.

18. Schultheis AM, Lurje G, Rhodes KE, Zhang W, Yang D, Garcia AA, et al. Polymorphisms and clinical outcome in recurrent ovarian cancer treated with cyclophosphamide and bevacizumab. Clin Cancer Res. 2008; 14: 7554-7563. 
19. Clark JJ, Provenzano M, Diggelmann HR, Xu N, Hansen SS, Hansen MR. The ErbB inhibitors, trastuzumab and erlotinib, inhibit growth of vestibular schwannoma xenografts in nude mice: A preliminary study. Otol Neurotol. 2008; 29: 846.

20. Fong B, Barkhoudarian G, Pezeshkian P, Parsa AT, Gopen Q, Yang I. The molecular biology and novel treatments of vestibular schwannomas. J Neurosurg. 2011; 115: 906-914.

21. Prior IA, Lewis PD, Mattos C. A comprehensive survey of Ras mutations in cancer. Cancer Res. 2012; 72: 2457-2467.

22. Downward J. Targeting RAS signalling pathways in cancer therapy. Nat Rev Cancer. 2003; 3: 11-22.

23. Janes MR, Zhang J, Li LS, Hansen R1, Peters U, Guo X, et al. Targeting KRAS mutant cancers with a covalent G12C-specific inhibitor. Cell. 2018; 172: 578-589.

24. Cox AD, Fesik SW, Kimmelman AC, Luo J, Der CJ. Drugging the undruggable RAS: Mission possible? Nat Rev Drug Discov. 2014; 13: 828-851.

25. Morrison H, Sperka T, Manent J, Giovannini M, Ponta H, Herrlich P. Merlin/neurofibromatosis type 2 suppresses growth by inhibiting the activation of Ras and Rac. Cancer Res. 2007; 67: 520-527.

26. Sato T, Sekido Y. Nf2/merlin inactivation and potential therapeutic targets in mesothelioma. Int J of Mol Sci. 2018; 19: 988.

27. Brastianos PK, Horowitz PM, Santagata S, Jones RT, McKenna A, Getz G, et al. Genomic sequencing of meningiomas identifies oncogenic SMO and AKT1 mutations. Nat Genet. 2013; 45: 285-289.

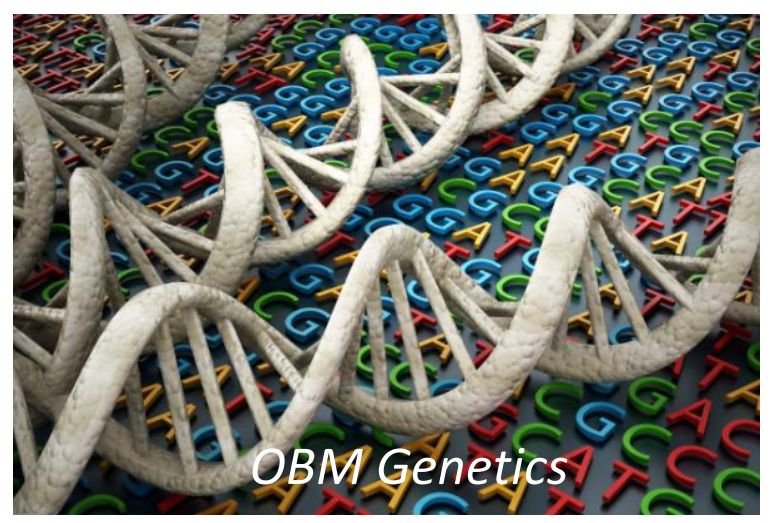

Enjoy OBM Genetics by:

1. Submitting a manuscript

2. Joining in volunteer reviewer bank

3. Joining Editorial Board

4. Guest editing a special issue

For more details, please visit:

http://www.lidsen.com/journals/genetics 